\title{
A Good Doctor
}

Sarosh Saleem

From early childhood, I knew I would become a doctor. My father dreamt of me becoming a doctor when he held me in his arms for the very first time. My mother proudly accompanied to my graduation ceremony 24 years later. I became a doctor. Whenever, during this time, I asked my grandmother to pray for me, so that I got good grades and became a doctor, she'd always pray and wish for me to become a good doctor. I studied and trained at the best institutions in the country. I did house job and residency. I learned how to take a 'history' from a patient. What to ask the parents of sick kids. What to look for in the physical examination of sick patients, crying babies, nervous teenagers, fragile elders and unconscious brains. I familiarized myself with all the investigations to request for, when patients presented with varying symptoms that were often non-specific or unique. I recognized rationales of ordering an X-Ray, Ultrasound or MRI scan in order to dig the best information about the underlying cause of the signs and symptoms. Which blood tests will better reveal the mystery of the disease that is making my patient feel sick? I was taught that. I was trained to correlate the history with the physical examination and the laboratory findings. I learned to understand the statistics, the incidence and prevalence of certain illnesses in our part of the world. I also learned the interpretation of documented evidence and statistical results to help in diagnosis and prediction of prognosis of the patients. Ever since I started studying at medical school, it has been an adventurous ride for me. A commitment for life. An endeavor of emotions and morals; hope and despair; humility and spirituality. I have cried when a patient passed away and rejoiced when one stepped closer to getting better. I felt proud when I was the one to catch the missing link of a crucial diagnosis and disappointed when I made a mistake. I celebrated with the nurses and doctors of my team whenever a critically ill patient was successfully resuscitated. I have held hands of a distraught mother as I shared details of illnesses and prognoses that would alter her life forever. After all the education and training as a doctor, I still have so much to learn. I have to learn how parents make decisions for their babies yet to be born or how a son decides for his ailing mother. What makes a patient agree or disagree with the treatment plan suggested by clinicians constantly puzzles me. I know how to diagnose or treat certain diseases but don't know how to prevent heartache of parents losing their child. I have yet to learn the right words to say to the people searching for hope and faith amongst pain and sickness. I am looking for what miracles and faith means for people in despair. How to be empathetic and yet respect boundaries, be decisive yet accommodating to patients' needs. I am searching for many answers that make any doctor, a good doctor. I hope my grandmother is still praying for me in heavens because yes, I am a doctor but only to wonder if I am a good doctor!?

\section{Corresponding Author:}

Dr. Sarosh Saleem

Department of Bioethic

Shalamar Medical \& Dental College, Lahore

Email address:

drsarosh@hotmail.com

Journal of Shalamar Medical and Dental College formerly known as Medical Journal of Sakina Begum Institute. 2019; Vol.1 (1) 